\title{
Manufacture of the ALS Storage Ring VacuUm System*
}

\author{
Kurt Kennedy
}

\author{
Advanced Light Source \\ Accelerator and Fusion Resparch Division \\ Lawrence Berkeley Laboratory \\ 1 Cydotron Road \\ Berkeley, CA 94720
}

\section{DISCLAIMER}

\begin{abstract}
This report was preparod as an acconat of woth aponeored by an apency of the United States Goverpment. Neriber the Unjted Sistes Gowernment sor any ateacy therof, nor any of their employees, makes any warranty, expres or inpliod, or asumes any legal liability or rapousi-

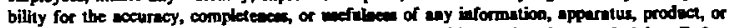
process discloed, or represests that is use would oot infriage privaledy owned rights. Reference berein to any speciric corrmencial product, proces, or service by trade anme, trademart,

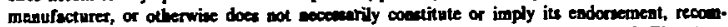
mendation, or favoring by the United States Government or any apency thereof. The view and opinions of authors exprened berein do eot necenarily state or rafket those of the United Stales Governmeat or any afency thereof.
\end{abstract}

November 13, 1990

Paper Presented at the Vacuum Design of Synchrotron Light Sources Conference, Argonne, Illinois, November 13-15, 1990

"This work was supported by the Director, Office of Energy Reseanch, Office of Batic Energy Sciences, Materials Sciences Division of the U.S. Department of Enerby, under Centrect No. DE-ACus-769F00ss 


\title{
MANUFACTURE OF THE ALS STORAGE RING VACUUM SYSTEM*
}

\author{
Kurt Kensidy \\ Lawrence Berkeley Laboratory, \\ University of California, Berkeley, CA 94720
}

\section{ABSTRACI}

The Advanced Light Source (ALS) storage ring has a 4.9 meter magnetic radius and an antechamber type vacuum chamber. These two requirements makes conventional bent tube manufacturing techniques difficult. The ALS sector vacuum chambers have been made by machining two halvec out of aluminum plate and welding at the mid plane. Each of these chambers have over 50 penetrations with metal sealed flanges and seven metal sealed poppet valves which use the chamber wall as the valve seat. The sector chambers are 10 meter long and sorne features in the chambers must be located to $.25 \mathrm{~mm}$. This paper describes how and how successfully these features have been achieved.

\section{INTRODUCTION}

The ALS is a synchrotron light source with an electron storage ring that requires a vacuum system with an small electron channel and very low pressure. An antechamber ${ }^{1}$ type vacuum system was chosen because it:

1) Improves longitudinal conductance

2) Lowers impedance

3) Permits adsorption of photons away from the electron beam and close to discrete pumping

4) Gives freedom to make vacuum penetrations for photon lines, diagnostic ports, pumps, etc

Fig. 1 shows the cross section of such a vacuum vessel with an antechamber .

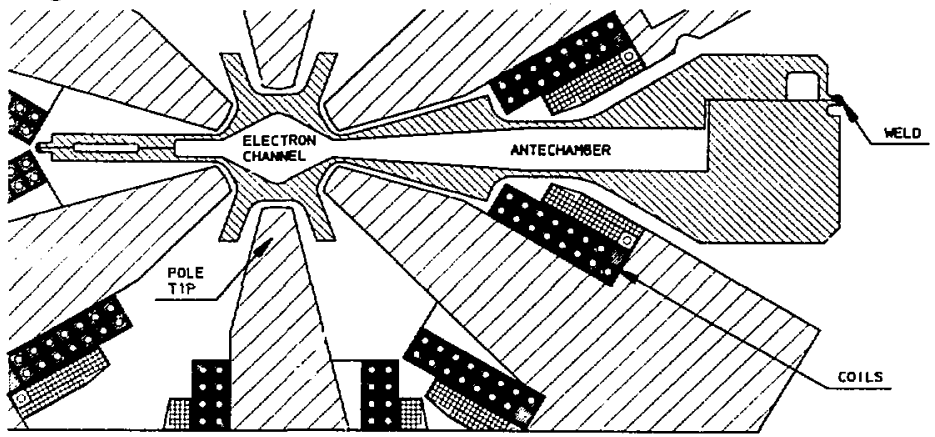

$x=2115-1342$

Fig. 1 Section of the vacuum vessel with antechamber at the sextupole - This work was supponed by the Director, Office of Energy Research, Office of Basic Energy Sciences Division, of the U.S. Department of Energy under Contract No. DE-AC03-76SF00098 
The benefits of an antechamber are not without a price. A lot more surface, with attendant outgassing, is expored the vacuum and the span of metal subjected to vacuum load is much larger. The thickness of metal required to limit the vacuum deflection to $0.1 \mathrm{~mm}$ is over $20 \mathrm{~mm}$ for aluminum. The traditional manufacturing method of extrusion and bending seemed impossible because of the relatively small Inagnetic radius and the added width that the antechamber required. A machined aluminum chamber was pursued.

\section{DESIGN OF A MACHINED VACUUN: CHAMBER}

Vacuum chambers machined in two halves and welded on the mid plane offer design freedoms that off set some of the inherent problems of this technique. Fig.2 shows how integral ribbing between magnet pole tips can support the vacuum load and keep the vacuum wall as thin as $1 \mathrm{~mm}$. Flanges can be machined directly into the chamber. Complex shapes can be created, such as electron channels that follow the beam stay clear.

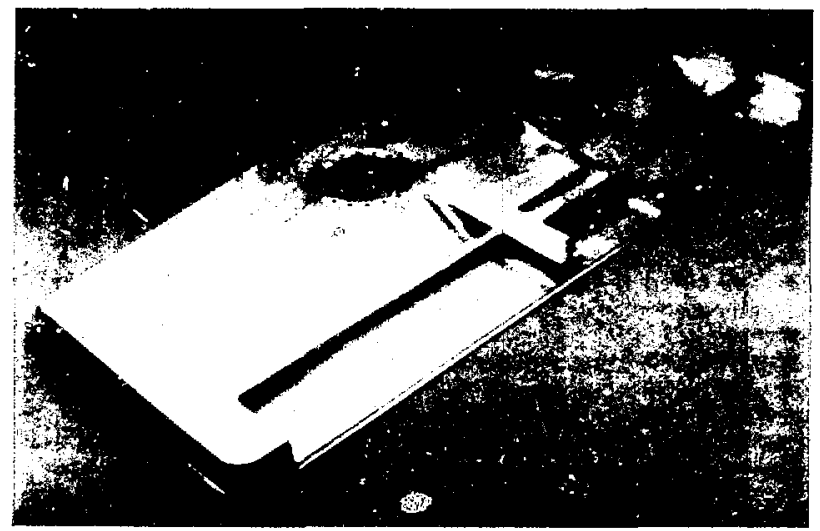

CB日 883-2272

Fig. 2 Picture of a section of the vacuum chamber at the sextupole and quadrupole

The ALS vacuum system divides up in such a way that, it is logical to machine the 10 meter sector chambers as a unit. The dimensional accuracy required for such a chamber is $0.25 \mathrm{~mm}$, making Computer Aided Design (CAD) a near necessity and the complexity is such that 8 megabits of CAD memory is needed for two dimensional drafting on half of a complete chamber. Feetures that must register top to bottom must have adjustability equal to about one ten thousandth the largest dimension of the chamber.

The selection of the aluminum alloy was based on distortion and ease of welding. The alloy need only be strong enough to resist plastic deformation from the metal gasket material used in the flanges. The alloy selected was 5083, which is a solid solution alloy, strengthened primarily with magnesium and has a minimum yield of $215 \mathrm{MPa}$ ( $31 \mathrm{ksi}$ ) with a $\mathrm{H32} 1$ temper. This alloy is a nonheat treatable alloy free of the residual stress associated quenching and with good welding and machining 


\section{CHAMBER CLEANING AND ASSEMBLY}

The size of the vacuum chamber made a non-immersion cleaning process necessary. The parts had to be cleaned hanging from a crane using men with brushes. The cleaning process had to be compatible with the workmen and the floor drain, that went to the sanitary sewer. The procedure used was: steam clean for gross oil removal and heating, scrub the surface with detergent, scrub the surface with a proprietary ${ }^{3}$ mild alkaline cleaner, rinse with copious amounts the hot deionized water and blow dry with liquid nitrogen boil off.

The perimeter was sealed with a filet weld using a hand held TIG torch and added 5183 alloy. The potential virtual leak at the mid plane of the chamber was vented by a channe! just inside the weld and this channel was flooded with argon during welding. Features that required good top to bottom registry, such the electron channel and valves parts, had special alignment tooling to insure optimal distribution of errors. The assembled vacuum is shown in Fig. 5

The combined machining and distortion error in the vertical direction was negligible small and the chamber lay on a granite flat without measurable gap. In the transverse direction, the maximum combined error was about $3 \mathrm{~mm}$ and this error could be reduced to $0.3 \mathrm{~mm}$ with modest lateral forces applied by the chamber support system. The longitudinal error is dominated thermal dilation and tends to be less important then errors in the other axes.

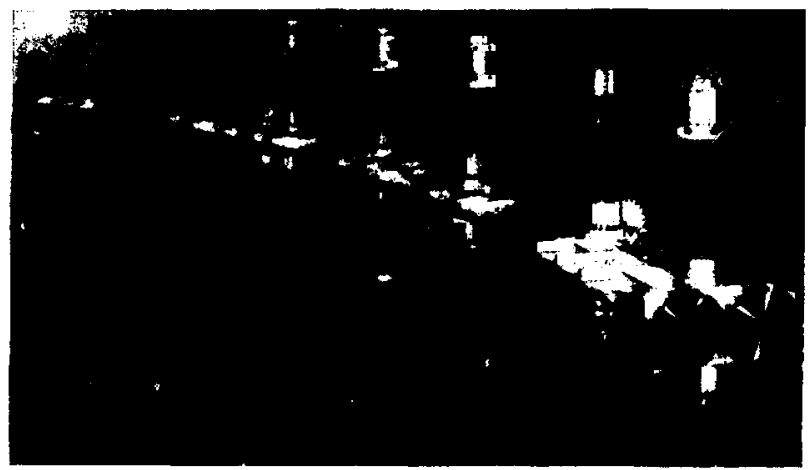

Fig. 5 Picture of an assembled ALS sector chamber

$\operatorname{ces} 800-10007$

\section{VACUUM PERFORMANCE}

The vacuum chamber was vacuum baked to $150^{\circ} \mathrm{C}$ for 24 hours using 20 permanently mounted strip heaters with a total capacity of $24 \mathrm{KW}$. The heavy aluminum cross section of chamber permitted the use of modest insulation and still maintain acceptable temperanure gradients. The chamber achieved $3 \times 10^{-10}$ Tor in 48 hours using only ion pumps, whose cumulative speed was $420 \mathrm{l} / \mathrm{s}$. Based on the geometric area, this would indicate mediocre but adequate outgassing rate of $10^{-12}$ 
proprieties. This alloy is copper free and does not have to be nitric acid rinsed after mild caustic cleaning. This permits the cleaning process to be drained to a sewer.

\section{FLANGES}

The design of flanges that could seal directly to the vacuum chamber had to take account of the relative softness of $5083 \mathrm{H} 321$ aluminum. A conflat type design requires much harder aluminum than 5083. Metal $O$ rings requires a very smooth surface for sealing and it was felt that the flange surfaces machined into the vacuum chamber would offer too great a scratch hazard. The sealing system selected was one derived from a high pressure Mott seal2. A cross section of the seal is shown in Fig. 3. The sealing surfaces are out of harms way and oriented such that the tool marks of an end mill lay perpendicular to the leak path. The flange thickness and bolt schedule are the same as standard conflats. Almost 1000 of these seals are used in the ALS storage ring.

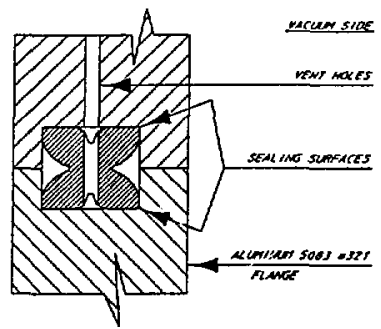

Fig. 3 Metal seal system

\section{CHAMBER MACHINING}

Numerically controlled milling machines capable of making parts four by thirty meters have developed to serve the needs of the aircraft industry Fig 4.. These machines have three spindles, each in effect have five axis of motion and three parts can be made simultaneously. These machines are well suited for making vacuum chambers except that their usual mission use aircraft rather than accelerator accuracy. Every $1^{\circ} \mathrm{C}$ change in the ALS chamber temperature changes it's length by $0.25 \mathrm{~mm}$. This large thermal dilation occurs in the relatively innocuous longitudinal direction. The part must, however, be clamped during machining so that thermal expansion and contraction originate from a single point near the center of the part and when the part returns to starting temperature the part is in the exact starting place.

The machining procedure consisted of: blank the plate to within $6 \mathrm{~mm}$ of the perimeter of the part, rough machining all surfaces to with in $2.5 \mathrm{~mm}$ of finish size, release all restraints for 24 hours, reclamp and finish machine. The time to machine three complete chambers was 750 hours. Hand finishing added another 100 hours.

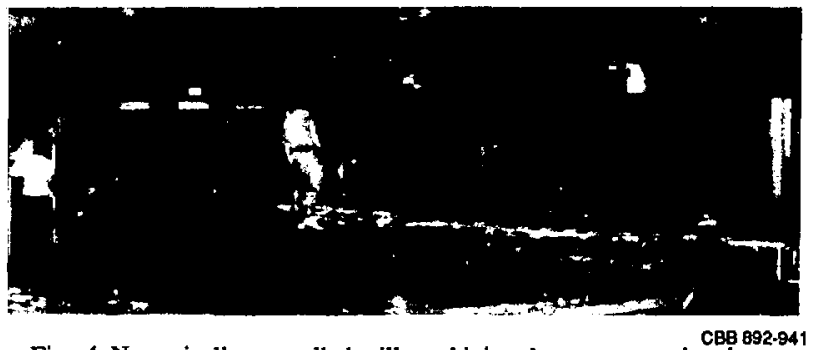

Fig. 4 Numerically controlled mill machining three vacuum chambers 
$T V / \mathrm{s} / \mathrm{cm}^{2}$. This relatively high outgassing rate is the result of the machining techniques used to minimize fabrication cost. Much of the metal removal was be done with convex end mills whose center moves very slowly and leaves a rough surface.

\section{DISCUSSION}

Machining techniques produced very compiex ALS sector vacuum chambers with good dimensional accuracy and acceptable vacuum properties but no discussion of fabrication method would be complete without mentioning economics. The cost of the aluminum and machining for one chamber was $\$ 75 \mathrm{~K}$ not including tooling and programing. If these fixed costs are distributed over 12 chambers, the unit price goes to $\$ 80 \mathrm{~K}$. An additional 600 hours of cleaning, welded and assembly were needed to complete each chamber. The total cost per meter, not including purmps, of an ALS sector chamber is about $\$ 10 \mathrm{~K}$.

$\$ 10 \mathrm{~K} /$ meter is a very large cost if compared to a simple extrusion, however, there are ameliorating factors. Each meter of chamber will have, on average, 5 all metal flanges. Large aluminum pieces were salvaged which will supply all the metal for 12 insertion device chambers. Without machining, magnet gaps would have be increase $10 \mathrm{~mm}$ (gradient) to $30 \mathrm{~mm}$ (sextupole). This increase translates into between $\$ 12 \mathrm{~K}$ and $\$ 31 \mathrm{~K}$ per meter increase in magnet cost depending on how cost scales with aperture. This analysis would imply that if magnet apertures can be reduced by about $10 \%$ by machining vacuum chambers, you can't afford not to.

\section{REFERENCES}

1. Kurt Kennedy, Topical Conference on: Vacuum Design of Advanced and Compact Synchrotron Light Sources, 52, (1988)

2. Fred Middleton, IEEE Transactions on Nuclear Science, Vol. NS-28, No. 3, 3298, (1981) 